\title{
Nutritional Assessment of Children Admitted at the Children's Ward of the Volta Regional Hospital
}

\author{
Clifford Afu \\ Department of Physician Assistantship, University of Health and Allied Sciences, Ho, Volta Region, Ghana \\ Email: cliffafu@gmail.com
}

How to cite this paper: Afu, C. (2017) Nutritional Assessment of Children Admitted at the Children's Ward of the Volta Regional Hospital. Open Access Library Journal, 4: e3690.

https://doi.org/10.4236/oalib.1103690

Received: May 24, 2017

Accepted: June 20, 2017

Published: June 23, 2017

Copyright $\odot 2017$ by author and Open Access Library Inc.

This work is licensed under the Creative Commons Attribution International License (CC BY 4.0).

http://creativecommons.org/licenses/by/4.0/

\section{(c) (i) Open Access}

\begin{abstract}
Background: In Ghana, nutritional assessment is not mandatory and as such majority of Children with nutritional challenges are unidentified and unmanaged; this is of a major concern knowing that malnutrition continues to be a leading cause of morbidity and mortality in most developing countries with Ghana as no exception and as such requires a lot of attention as a basis for prompt dietetic referral. Objective: To assess the practice regarding the measurement and documentation of anthropometric parameters of children age between 6 - 59 months admitted at the Volta Regional Hospital. Methodology: This was a one year retrospective review of sampled pediatric admissions at the Volta Regional Hospital. Results: Out of 242 folders reviewed, only 34 children (14\%) had their MUAC documented. Height was measured in 0.4\% of admitted patients. Weight was checked for $89.7 \%$ of folders reviewed making it the parameter with the highest level of monitoring. Growth problems were undiagnosed in $87.5 \%$ of patients with growth problems and likewise $85 \%$ of patients who were underweight were undiagnosed as a result of no nutritional assessment. Conclusions: There is the need for this study to be conducted on a regional and a national level. In spite of the many advances in medicine and clinical care, appropriate nutritional assessment of hospitalized patients appears to be overlooked or not considered as a sufficient medical priority. There is an urgent need to make nutritional assessment routine for all hospitalized children.
\end{abstract}

\section{Subject Areas}

Nutrition

\section{Keywords}

Malnutrition, Nutritional Assessment, Hospitalized Patients, Admission 


\section{Introduction}

World Food Programme defines malnutrition as "a state in which the physical function of an individual is impaired to the point where he or she can no longer maintain adequate bodily performance process such as growth, pregnancy, lactation, physical work and resisting and recovering from disease" [1]. The term malnutrition is used interchangeably with "under nutrition" in some studies [2]. Malnutrition is noted to be associated with varying negative patient outcomes, notably higher infection rates [3] [4] [5] [6], increased rate of muscle loss [4] [7] [8], longer length of hospital admission [8] [9] [10], increased morbidity and mortality [11] [12] [13] [14] and impaired wound healing [4] [6] [7].

Globally, an estimated 150 to 200 million children under five years are said to be underweight and stunted [15]. Nine million children across the world die yearly before the age of 5 years and one-third of these deaths are caused by under nutrition [16].

In Ghana, malnutrition among children below five years continues to be one of the country's major human development challenges [17]. The overall health status of children in Ghana has improved over the last 10 years but there still exist a significant number of cases of malnutrition in the rural areas [18]. It is estimated that one out of every 10 children in Ghana is severely stunted and most of these cases of stunting are as a result of inability of children to receive adequate nutrition of good quality over a long period [18]. The Volta region is among the top 3 regions with high prevalence rate of malnutrition with an estimated prevalence rate of $19 \%$ [18].

A child's nutritional status is a very important marker in the overall developmental process of that child [18]. With good nutrition comes an array of positive outcomes for the child and the family at large; an improved nutritional status of a child under five implies low mortality and as such has a good growth curve with improved cognitive skills and greater output in adulthood [18].

Nutritional health promotion has been the key element in primary health care and hence it is important to periodically monitor the same [18]. In the United Kingdom and the United States, routine nutritional screening of hospitalized patients is mandatory, and as such serves as a prerequisite for obtaining accreditation [19] but surprisingly most children who visit the hospitals in most developing countries including Ghana are not screened for signs of malnutrition [20]. This can be attributed to the lack of simple and feasible screening techniques [20].

Measurement of mid arm circumference, weight and height are simple and cost effective tools for community assessment of malnutrition [20]. Early detection of nutritional deficiencies and the provision of quick intervention can correct the nutritional status of most children and subsequently improve disease outcome [21].

This study measured the level of nutritional assessment done at the Volta Regional Hospital. 


\section{Methodology}

\subsection{Study Area}

The study was conducted at the Volta Regional Hospital (VRH). The VRH serves as a referral point for all other hospitals in the Volta region and as such serve a varying cluster of people from various parts of the region and beyond. The Hospital has a staff strength of about 452 . The total bed capacity of the hospital is 240 and that of the children's ward is 25 . The hospital is located at the regional capital Ho with a total population of about 177,281 representing 8.4 percent of the region's total population.

\subsection{Study Design}

This was a retrospective, descriptive study of the nutritional status of children aged 6 to 59 months admitted at the hospital during the study period (January 2015 to December 2015). The total admission within the targeted age group (6 to 59 months) for the year under review was 565 patients. The folder numbers of patients who were admitted in the year under review were retrieved from the HAMS and records of 242 admitted patients whose ages were in the desired age group were sampled. The sample size was determined by calculations based on the following formula; $n=Z^{2}(p q) / d$ [22]. The statistical certainty chosen is $95 \%$ level of confidence, hence $\mathrm{z}=1.96$. The estimated rate $(p)$ for the indicators to be studied, that is stunting and underweight and wasting are $19.3 \%, 10.5 \%$, and $2.5 \%$, respectively in the Volta region (GDHS, 2014). The margin of error allowed, $(d)$ is $5 \%$ or 0.05 . Since the estimated $p$ for stunting was higher $n$ was calculated using the level of stunting thus; $n=(1.96)^{2} \times(0.19 \times 1-0.19) /(0.05)^{2}=$ 236. However, to ensure ease of statistical calculation the minimum sample size was rounded up to 240 , with the knowledge that this will not reduce the strength of the study. Patients who were sampled but their folders could not be traced were replaced with other patients.

Data was collected on patient's demographic data, family and social history, socio demographic and socio-economic status of the child, anthropometric data of the child, past and present medical history of the child and feeding pattern of the child, admission and discharge diagnosis, and residence and referral status if patient was referred from another facility with a pre tested questionnaire.

\subsection{Data Entry, Management and Analysis}

Data collected was entered into an excel spread sheet and tabulated according to the various socio-economic and anthropometry findings, and was analyzed using statistical software SPSS 23.0 for windows (SPSS Inc., Chicago, IL, USA). WHO Anthro was used to classify the study children into categories of nutritional status by converting the anthropometric measurements into z-scores of weight for age (WAZ) and MUAC for Age.

\subsection{Ethical Clearance}

Ethical clearance was obtained from the Ghana health service Ethics Review 
Committee (ERC) with protocol ID NO: GHS-ERC 59/02/15.

\section{Result}

This study is comprised of 242 sampled under five years admitted patients in the year 2015 of which $58.7 \%$ were males and $41.3 \%$ females. The majority of children were between 12 - 23 months (44.6\%). Majority of the children had no formal education (76.4) with a mean age of 27 months. Ewes represented the majority ethnic group (94.6\%) with Christianity being the dominant religious inclination among participants (95\%) with $4.5 \%$ being Muslims. Children dwelling in urban areas were $50 \%$ whereas $31.8 \%$ were peri urban dwellers and the minority living in the rural areas (16.5\%). The residential status of 4 children was not documented. Out of 140 documented employment status of parents, majority of them were in the informal sector (63.5\%).

From Table 1, regarding the measurement of anthropometric parameters, out of 242 folders sampled, only 34 children (14\%) had their MUAC documented. The age group with most frequent MUAC measurement whiles on admission was children between 12 and 23 months 26 (24.1\%). There was no MUAC documented for children in the age group $36-47$ months. Weight was measured for $217(89.7 \%)$ of the admitted children as against 26 (10.3\%) who had no form of documentation of weight being checked throughout their stay on admission. Children within the age range of $12-23$ months had the most number of measurements (98 recorded measurements).

Majority of children 241 (99.6\%) admitted never had their heights checked throughout their stay on admission. Out of the 242 sampled cases, only one patient from the age range of 48 - 57 months had the height measured.

Table 2 shows the number of children who had growth issues but were undiagnosed and unassessed for signs of malnutrition. Majority of children with growth problems $14(87.5 \%)$ were undiagnosed as against $2(12.5 \%)$ who were identified and diagnosed appropriately. Although 53 (21.9\%) of the sampled

Table 1. Measurement of the anthropometric parameters of children age between 6 - 59 months admitted at the Volta Regional Hospital.

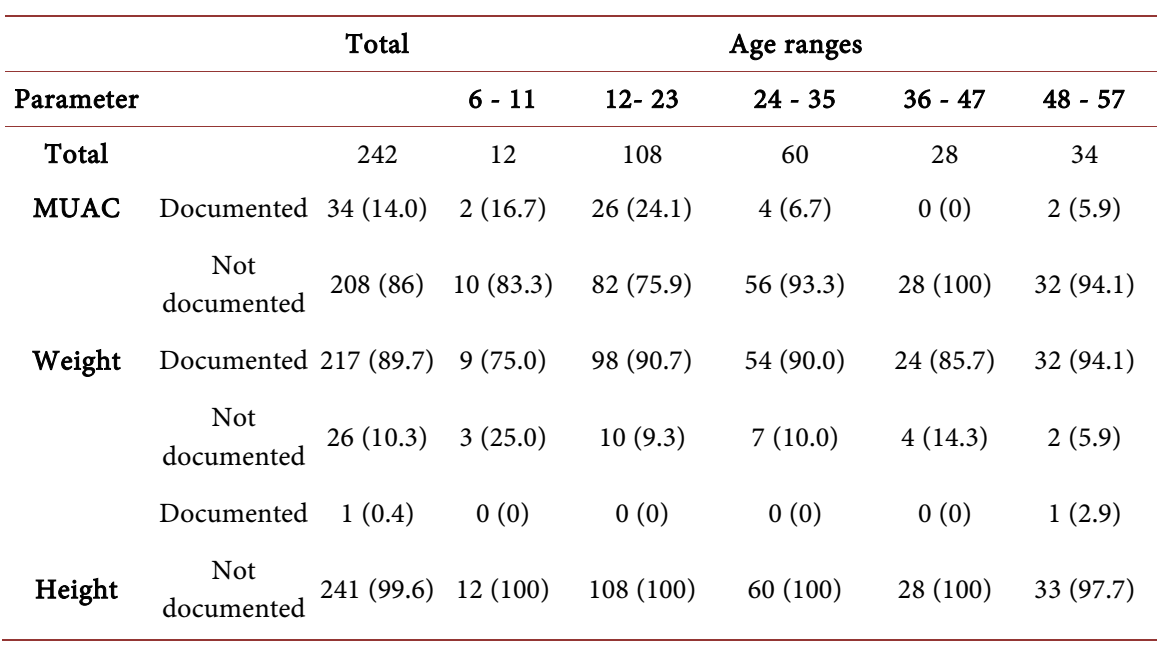


Table 2. Number of malnutrition cases undiagnosed who had growth issues.

\begin{tabular}{cccccc}
\hline \multicolumn{2}{c}{ Parameter } & Growth problem & $\begin{array}{c}\text { Normal } \\
\text { growth }\end{array}$ & Underweight & $\begin{array}{c}\text { Severe } \\
\text { underweight }\end{array}$ \\
\hline \multicolumn{2}{c}{ Total } & $16(100)$ & $148(100)$ & $20(100)$ & $33(100)$ \\
Malnutrition & Diagnosed & $2(12.5)$ & $8(5.4)$ & $3(15.0)$ & $15(45.5)$ \\
& Not diagnosed & $14(87.5)$ & $140(94.6)$ & $17(85.0)$ & $18(54.5)$ \\
\hline
\end{tabular}

children were underweight, only 18 (7.4\%) of them were assessed and diagnosed rendering 35 (66\%) unassessed and undiagnosed. There was a documented dietician request for $31(13.2 \%)$ of the total sampled patients with 25 (10.7\%) receiving dietician review and $18(7.6 \%)$ receiving a follow up.

\section{Discussion}

When children are ill enough to be hospitalized, it be would expected that growth assessment will be a part of their routine assessment. Regarding the practice of nutritional assessment at the VRH, it was observed that there was no documentation of MUAC measurement for 208 (86\%) of the total number of admitted patients with only 33 (14\%) being documented similar other findings [23]. Most of the people who had their MUAC measurements taken were those with signs and symptoms of severe malnutrition. It was also noted that admitted patients who showed no clinical sign of malnutrition or appear healthy do not have their MUAC values taken making it difficult to get the real picture of the nutritional status of the children.

As a routine measurement, almost all admitted children 217 (89.7\%) had their weight taken at one point in time of their stay on admission similar findings of another study [23]. Since the recent weight of participants were not known it was difficult to determine if their weight was increasing or decreasing. There is therefore the need for serial weight measurement to assess and measure improvement in the nutritional state of children.

Only 2 participants representing $0.4 \%$ of the total number of participants had their heights measured and documented. It was clear that height measurement was not a routine assessment done for admitted patients [23] although it is highly recommended [23]. As such, the BMI of admitted patients cannot be calculated similar to findings from a Canadian report [23]. This is of a major concern as it is reported that about $26 \%$ of children admitted to a referral hospital may be malnourished [24].

Children with MUAC values below $12.5 \mathrm{~cm}$ or weight-for-height $\mathrm{Z}$ score (WHZ) below -2 standard deviation were considered as malnourished [15].

Children who came to the hospital either moderately underweight or severely underweight 53 (21.9\%) had no proper nutritional assessment done on them and as such were discharged without any dietetic referral.

\section{Conclusion}

In spite of the many advances in medicine and clinical care, appropriate nutri- 
tional assessment of hospitalized patients appears to be overlooked or not considered as a sufficient medical priority. Most of the hospitalized children did not have any form of nutritional assessment done as it was evident that nutrition screening was done mainly for those who presented classical signs and symptoms of malnutrition. In order to avert the poor health outcomes associated with children with malnutrition, it is important that routine screening be embedded in the regular health care service provision so as to identify and prescribe an appropriate nutritional support and a possible early dietetic referral. Serial measurement of weight as well as height and MUAC measurement should be a routine assessment for all hospitalized patients as this will help identify children who present other conditions but are also malnourished. It is also very important that this study is conducted on a regional level in order to evaluate the magnitude of this problem.

\section{References}

[1] WFP (2005) A Manual: Measuring and Interpreting Malnutrition and Mortality. Geneva.

[2] Seetharaman, N., Chacko, T.V., Shankar, S. and Mathew, A.C. (2007) Measuring Malnutrition-The Role of $\mathrm{Z}$ Scores and the Composite Index of Anthropometric Failure (CIAF). Indian Journal of Community Medicine, 32, 35-39. https://doi.org/10.4103/0970-0218.53392

[3] Baldwin, C. and Parsons, T.J. (2004) Dietary Advice and Nutritional Supplements in the Management of Illness-Related Malnutrition: Systematic Review. Clinical Nutrition, 23, 1267-1279. https://doi.org/10.1016/j.clnu.2004.07.018

[4] Chandra, R.K. (1997) Nutrition and the Immune System: An Introduction. The American Journal of Clinical Nutrition, 66, 460S-463S.

[5] DiMaria-Ghalili, R.A. (2002) Changes in Nutritional Status and Postoperative Outcomes in Elderly CABG Patients. Biological Research for Nursing, 4, 73-84. https://doi.org/10.1177/1099800402238330

[6] Hoffer, L.J. (2001) Clinical Nutrition: 1. Protein-Energy Malnutrition in the Inpatient. Canadian Medical Association Journal, 165, 1345-1349.

[7] Hill, G.L. and Jonathan, E. (1992) Rhoads Lecture. Body Composition Research: Implications for the Practice of Clinical Nutrition. Journal of Parenteral and Enteral Nutrition, 16, 197-218. https://doi.org/10.1177/0148607192016003197

[8] WFP (2005) A Manual: Measuring and Interprating Malnutrition and Mortality. Nutrition Service WFP, Rome, 1-222.

[9] Braunschweig, C., Gomez, S. and Sheean, P.M. (2000) Impact of Declines in Nutritional Status on Outcomes in Adult Patients Hospitalized for More than 7 Days. Journal of the American Dietetic Association, 100, 1316-1322. https://doi.org/10.1016/S0002-8223(00)00373-4

[10] Gout, B.S., Barker, L.A. and Crowe, T.C. (2009) Malnutrition Identification, Diagnosis and Dietetic Referrals: Are We Doing a Good Enough Job? Nutrition \& Dietetics, 66, 206-211. https://doi.org/10.1111/j.1747-0080.2009.01372.x

[11] Correia, M.I.T. and Waitzberg, D.L. (2003) The Impact of Malnutrition on Morbidity, Mortality, Length of Hospital Stay and Costs Evaluated through a Multivariate Model Analysis. Clinical Nutrition, 22, 235-239. https://doi.org/10.1016/S0261-5614(02)00215-7 
[12] Holmes, S. (2007) The Effects of Undernutrition in Hospitalised Patients. Nursing Standard, 22, 35-38. https://doi.org/10.7748/ns2007.11.22.12.35.c6242

[13] Kubrak, C. and Jensen, L. (2007) Malnutrition in Acute Care Patients: A Narrative Review. International Journal of Nursing Studies, 44, 1036-1054. https://doi.org/10.1016/j.ijnurstu.2006.07.015

[14] Middleton, M., Nazarenko, G., Nivison-Smith, I. and Smerdely, P. (2001) Prevalence of Malnutrition and 12-Month Incidence of Mortality in Two Sydney Teaching Hospitals. Internal Medicine Journal, 31, 455-461. https://doi.org/10.1046/j.1445-5994.2001.00109.x

[15] De Onis, M., Frongillo, E.A. and Blössner, M. (2000) Is Malnutrition Declining? An Analysis of Changes in Levels of Child Malnutrition Since 1980. Bulletin of the World Health Organization, 78, 1222-1233.

[16] Black, R.E., Allen, L.H., Bhutta, Z.A., Caulfield, L.E., De Onis, M., Ezzati, M., et al. (2008) Maternal and Child Undernutrition: Global and Regional Exposures and Health Consequences. The Lancet, 371, 243-260. https://doi.org/10.1016/S0140-6736(07)61690-0

[17] Nti, A. and Lartey, A. (2007) Young Child Feeding Practices and Child Nutritional Status in Rural Ghana. International Journal of Consumer Studies, 31, 326-332. https://doi.org/10.1111/j.1470-6431.2006.00556.x

[18] GDHS (2014) Ghana Statistical Service, Ghana Health Service and ICF Macro, Ghana Demographic Health Survey. Rockville, Maryland, USA.

[19] Elia, M., Zellipour, L. and Stratton, R.J. (2005) To Screen or Not to Screen for Adult Malnutrition? Clinical Nutrition, 24, 867-884. https://doi.org/10.1016/j.clnu.2005.03.004

[20] Barker, L.A., Gout, B.S. and Crowe, T.C. (2011) Hospital Malnutrition: Prevalence, Identification and Impact on Patients and the Healthcare System. International Journal of Environmental Research and Public Health, 8, 514-527. https://doi.org/10.3390/ijerph8020514

[21] Berkley, J., Mwangi, I., Griffiths, K., Ahmed, I., Mithwani, S., English, M., et al. (2005) Assessment of Severe Malnutrition among Hospitalized Children in Rural Kenya: Comparison of Weight for Height and Mid Upper Arm Circumference. JAMA, 294, 591-597. https://doi.org/10.1001/jama.294.5.591

[22] Snedecor, G., Cochran, W. and Ames, I.A. (1989) Analysis of Variance: The Random Effects Model. Iowa State University Press, Iowa City.

[23] Cummings, E.A., John, H., Davis, H.S. and McTimoney, C. (2005) Documentation of Growth Parameters and Body Mass Index in a Paediatric Hospital. Paediatrics \& Child Health, 10, 391-394.

[24] Hendricks, K.M., Duggan, C., Gallagher, L., Carlin, A.C., Richardson, D.S., Collier, S.B., et al. (1995) Malnutrition in Hospitalized Pediatric Patients: Current Prevalence. Archives of Pediatrics \& Adolescent Medicine, 149, 1118-1122. https://doi.org/10.1001/archpedi.1995.02170230072010 
Submit or recommend next manuscript to OALib Journal and we will provide best service for you:

- Publication frequency: Monthly

- 9 subject areas of science, technology and medicine

- Fair and rigorous peer-review system

- Fast publication process

- Article promotion in various social networking sites (LinkedIn, Facebook, Twitter, etc.)

- Maximum dissemination of your research work

Submit Your Paper Online: Click Here to Submit

Or Contact service@oalib.com 